\title{
220 Simultaneous measurement of three dimensional (3D) left and right ventricular volumes and ejection fraction during dobutamine cardiovascular magnetic resonance

\author{
Sangeeta Mandapaka*, Craig Hamilton, Kim Lane and William G Hundley
}

Address: Wake Forest University, Winston salem, NC, USA

* Corresponding author

from I th $^{\text {th }}$ Annual SCMR Scientific Sessions

Los Angeles, CA, USA. I-3 February 2008

Published: 22 October 2008

Journal of Cardiovascular Magnetic Resonance 2008, I0(SuppI I):A8I doi:I 0.I I86/I532-429X-I0-SI-A8I

This abstract is available from: http://jcmr-online.com/content/I0/SI/A8I

(c) 2008 Mandapaka et al; licensee BioMed Central Ltd.

\section{Introduction}

Appropriate displacement of blood volume from the right into the left ventricle via the pulmonary circulation is necessary to maintain forward cardiac output during stress and prevent inappropriate displacement of blood into the lungs by the right ventricle during left ventricular (LV) failure.

\section{Purpose}

Cardiovascular magnetic resonance (CMR) has been used to quantify LV and right ventricular (RV) volumes, and ejection fraction (EF) simultaneously at rest, but the feasibility of CMR to quantify simultaneous measures of RV and LV volumes and EF throughout the course of cardiovascular stress testing in humans is unknown.

\section{Methods}

Thirteen healthy subjects ( 5 women; $42 \%$ ), without medical conditions and taking no medications, aged $53+10$ years, underwent 2 CMR studies separated by 4 to 8 weeks in which dobutamine and atropine were infused to achieve $85 \%$ of the maximum predicted heart rate response (MPHRR) for age. Images were acquired with a 1.5 T Excite (General Electrical Medical Systems, Milwaukee, Wisconsin) whole body imaging system using a phased array a cardiac surface coil over the chest. Multislice, steady state free precession cine white blood images were acquired spanning the cardiac base to the apex. Image parameters included an $8 \mathrm{~mm}$ thick slice, a $2 \mathrm{~mm}$ gap, a $45 \mathrm{~cm}$ FOV, a $224 \times 160$ matrix, a $10 \mathrm{msec}$ repeti- tion time, a 3 msec echo time, a temporal resolution of 20 msec, a $125 \mathrm{~Hz} / \mathrm{px}$ band-width, and a flip angle of 50 degrees. Two slices were acquired in the multi-slice stack during 10 second periods of breath-holding. RV and LV volumes, and EF were determined using a Simpson's Rule technique in which the endocardial surface was identified at end-diastole and end-systole in each slice and multiplied by the slice thickness and number of slices to determine the volumes for the respective LV and RV cavities.

\section{Results}

All data are expressed as mean + standard deviation. At rest, low dose dobutamine $(7.5 \mathrm{mcg} / \mathrm{kg} / \mathrm{min})$, and peak stress, the heart rates, systolic, and diastolic blood pressures for the participants were $65+10,137+16$, and 83 $+15 ; 81+13,39+18 ;$ and $78+13 ; 134+13,151+18$, and $71+15$, respectively on exam 1 , and, $64+10,139+$ 16 , and $80+12 ; 81+13,141+16$, and $80+8 ; 133+10$, $155+20$, and $78+11$, respectively, on exam $2(\mathrm{p}=0.003$, $0.008,0.02 ; 0.004,0.006,0.09 ; 0.11,0.007,0.4$ for all comparisons of like terms between exam 1 and 2). The RV and LV end-diastolic (EDV), end-systolic (ESV), and stroke volumes (SV), as well as EF for each level of stress during exam 1 and 2 are shown in the Tables $(1 \& 2)$. RV and LV SV were highly correlated at each level of stress (rest, $\mathrm{r}=0.446$; low dose, $\mathrm{r}=0.619$; peak stress, $\mathrm{r}=0.362$ ). Also, the mean difference in $\mathrm{SV}$ at each level of stress (rest, $\mathrm{p}=0.0007$; low dose, $\mathrm{p}=0.0012$; peak stress, $\mathrm{p}=0.0014$ ) was similar between exam 1 and 2 . 


\section{Conclusion}

Simultaneous change in RV and LV stroke volume can be assessed in a highly reproducible manner throughout the course of pharmacologic stress administered to achieve $85 \%$ of MPHRR for age. This noninvasive methodology will be useful to further study the interdependence of RV and LV stroke volume during various forms of stress, and identify inappropriate displacement of blood flow into the lungs in patients with dyspnea.

Publish with Biomed Central and every scientist can read your work free of charge

"BioMed Central will be the most significant development for disseminating the results of biomedical research in our lifetime. " Sir Paul Nurse, Cancer Research UK

Your research papers will be:

- available free of charge to the entire biomedical community

- peer reviewed and published immediately upon acceptance

- cited in PubMed and archived on PubMed Central

- yours - you keep the copyright

Submit your manuscript here:

http://www.biomedcentral.com/info/publishing_adv.asp 